\title{
Reducing Psychological Resistance to Digital Repositories
}

The potential value of digital repositories is dependent on the cooperation of scholars to deposit their work. Although many researchers have been resistant to submitting their work, the literature on digital repositories contains very little research on the psychology of resistance. This article looks at the psychological literature on resistance and explores what its implications might be for reducing the resistance of scholars to submitting their work to digital repositories. Psychologists have devised many potentially useful strategies for reducing resistance that might be used to address the problem; this article examines these strategies and how they might be applied.

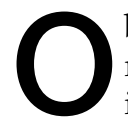
bserving the development and growth of digital repositories in recent years has been a bit like riding an emotional roller coaster. Even the definition of what constitutes a repository may not be the subject of complete agreement, but for the purposes of this study, a repository is defined as an online database of digital or digitized scholarly works constructed for the purpose of preserving and disseminating scholarly research. The initial enthusiasm expressed by librarians and advocates of open access toward the potential of repositories to make significant amounts of scholarly research available to anyone with Internet access gradually gave way to a more somber appraisal of the prospects of getting faculty and researchers to deposit their work. In August 2007, Bailey posted an entry to his Digital Koans blog titled "Institutional Repositories: DOA?" in which he noted that building digital repository collections would be a long, arduous, and costly process. ${ }^{1}$ The success of repositories, in his view, will be a function not so much of technical considerations as of attitudinal ones. Faculty remain unconvinced that repositories are important, and there is a critical need for outreach programs that point to repositories as an important step in solving the crisis in scholarly communication.

Salo elaborated on Bailey's post with "Yes, IRs Are Broken. Let's Talk About It," on her own blog, Caveat Lector. Salo points out that institutional repositories have not fulfilled their early promise of attracting a large number of faculty who are willing to submit their work. She criticizes repositories for monopolizing the time of library faculty and staff, and she states her belief that repositories will not work without deposit mandates, but that mandates are impractical. ${ }^{2}$

Subsequent events in the world of scholarly communication might suggest that mandates may be less impractical than Salo originally thought. Since her post, the National Institutes of Health mandate, the Harvard and MIT mandates, and other mandates such as the one instituted at Stanford's School of Education, have come to pass, and the Registry of Open Access Repository Material Archiving Policies (ROARMAP) lists more than 120 mandates around the world that now exist. ${ }^{3}$ While it is too early to tell whether these developments will be successful in getting faculty to deposit their work in digital repositories, they at least establish a precedent that other institutions may follow. How many institutions follow and how effective the mandates will be once enacted remains to be seen.

Will all colleges and universities, or even a majority, adopt mandates that require faculty to deposit their work in repositories? What of those that do not? Even if most institutions are successful in instituting mandates, will they be sufficient to obtain faculty cooperation? For those institutions that do not adopt mandates, how are they going to persuade faculty to participate in self-archiving, or even in some variation-such as having surrogates (librarians, staff, or graduate assistants) archive the work of faculty? Are mandates the only way to ensure faculty cooperation and compliance, or are mandates even necessarily the best way?

To begin to adequately address the problem of user resistance to digital repositories, it might help to first gain some insight into the psychology of resistance. The existing literature on user behavior with regard to digital repositories devotes scant attention to the psychology of resistance. In an article entitled "Institutional Repositories: Partnering with Faculty to Enhance Scholarly Communication," Johnson discusses the inertia of the traditional publishing paradigm. He notes that this inertia is most evident in academic faculty. This would suggest that the problem of eliciting user cooperation is primarily motivational and that the problem is more one of indifference than active resistance. ${ }^{4}$

Heterick, in his article "Faculty Attitudes toward Electronic Resources," suggests that one reason faculty may be resistant to digital repositories is because they do not fully trust them. In response to a survey he conducted, 48 percent of faculty felt that libraries should maintain paper archives..$^{5}$ The implication is that digital repositories and archives may never completely replace hard copies in the minds of scholars.

In "Understanding Faculty to Improve Content Recruitment for Institutional Repositories," Foster and Gibbons point out that faculty complain of having too much work already. They resent any additional work that contributing to a digital repository might entail. Thus the authors echo Johnson in suggesting that faculty resistance

Brian Quinn (brian.quinn@ttu.edu) is Social Sciences Librarian, Texas Tech University Libraries, Lubbock. 
may be attributed at least in part to motivation. ${ }^{6}$ In another article published a few months later, Foster and Gibbons suggest that the main reason faculty have been slow to deposit their work in digital repositories is a cognitive one: Faculty have not understood how they would benefit by doing so. The authors also mention that users may feel anxiety when executing the sequence of technical steps needed to deposit their work, and that they may also worry about possible copyright infringement. ${ }^{7}$ The psychology of resistance may thus manifest itself in both cognitive and affective ways.

Harley and her colleagues talk about faculty not perceiving any reward for depositing their work in their article "The Influence of Academic Values on Scholarly Publication and Communication Practices." This perception results in reduced drive to participate. Anxiety is another factor contributing to resistance: Faculty fear that their work may be vulnerable to plagiarism in an openaccess environment. ${ }^{8}$

In "Towards User Responsive Institutional Repositories: a Case Study," Devakos suggests that one source of user resistance is cognitive in origin. Scholars do not submit their work frequently enough to be able to navigate the interface from memory, so they must reinitiate the learning process each time they submit their work. The same is true for entering metadata for their work. ${ }^{9}$ Their sense of control may also be threatened by any limitations that may be imposed on substituting later iterations of their work for earlier versions.

Davis and Connolly point to several sources of confusion, uncertainty, and anxiety among faculty in their article "Institutional Repositories: Evaluating the Reasons for Non-use of Cornell University's Installation of DSpace." Cognitive problems arise from having to learn new technology to deposit work and not knowing copyright details well enough to know whether publishers would permit the deposit of research prior to publication. Faculty wonder whether this might jeopardize their chances of acceptance by important journals whose editors might view deposit as a form of prior publication that would disqualify them from consideration. There is also fear that the complex structure of a large repository may actually make a scholar's work more difficult to find; faculty may not understand that repositories are not isolated institutional entities but are usually searchable by major search engines like Google. ${ }^{10}$

Kim also identifies anxiety about plagiarism and confusion about copyright as being sources of faculty resistance in the article "Motivating and Impeding Factors Affecting Faculty Contribution to Institutional Repositories." Kim found that plagiarism anxiety made some faculty only willing to deposit already-published work and that prepublication material was considered too risky. Faculty with no self-archiving experience also felt that many publishers do not allow self-archiving, whether or not this was actually the case. ${ }^{11}$ This study also suggests that a combination of both cognitive and affective processes feed faculty resistance to digital repositories.

It can be seen from the preceding review of the literature that several factors have been identified as being possible sources of user resistance to digital repositories. Yet the authors offer little in the way of strategies for addressing this resistance other than to suggest workaround solutions such as having nonscholars (e.g., librarians, graduate students, or clerical staff) serve as proxy for faculty and deposit their work for them, or to suggest that institutions mandate that faculty deposit their work. Similarly, although numerous arguments have been made in favor of digital repositories and open access, they do not directly address the resistance issue. ${ }^{12}$ In contrast, psychologists have studied user resistance extensively and accumulated a body of research that may suggest ways to reduce resistance rather than try to circumvent it. It may be helpful to examine some of these studies to see what insights they might offer to help address the problem of user resistance.

It should be pointed out that resistance as a topic has been addressed in the business and organizational literature, but has generally been approached from the standpoint of management and organizational change. ${ }^{13}$ This study has chosen to focus primarily on the psychology of resistance because many repositories are situated in a university setting. Unlike employees of a corporation, faculty members typically have a greater degree of autonomy and latitude in deciding whether to accommodate new work processes and procedures into their existing routines, and the locus of change will therefore be more at an individual level.

\section{The psychology of user resistance}

Psychologists define resistance as a preexisting state or attitude in which the user is motivated to counter any attempts at persuasion. This motivation may occur on a cognitive, affective, or behavioral level. Psychologists thus distinguish between a state of not being persuaded and one in which there is actual motivation to not comply. The source of the motivation is usually an affective state, such as anxiety or ambivalence, which itself may result from cognitive problems, such as misunderstanding, ignorance, or confusion. ${ }^{14}$ It is interesting to note that psychologists have long viewed inertia as one form of resistance, suggesting paradoxically that a person can be motivated to inaction. ${ }^{15}$ Resistance may also manifest itself in more subtle forms that shade into indifference, suspicion of new work processes or technologies, and contentment with the status quo. 


\section{Negative and positive strategies for reducing resistance}

Just as the definition of resistance can be paradoxical, so too may be some of the strategies that psychologists use to address it. Perhaps the most basic example is to counter resistance by acknowledging it. When scholars are presented with a message that overtly states that digital repositories are beneficial and desirable, it may simultaneously generate a covert reaction in the form of resistance. Rather than simply anticipating this and attempting to ignore it, digital repository advocates might be more persuasive if they acknowledge to scholars that there will likely be resistance, mention some possible reasons (e.g., plagiarism or copyright concerns), and immediately introduce some counterrationales to address those reasons. ${ }^{16}$

Psychologists have found that being up front and forthcoming can reduce resistance, particularly with regard to the downside of digital repositories. They have learned that it can be advantageous to preemptively reveal negative information about something so that it can be downplayed or discounted. Thus talking about the weaknesses or shortcomings of digital repositories as early as possible in an interaction may have the effect of making these problems seem less important and weakening user resistance. Not only does revealing negative information impart a sense of honesty and credibility to the user, but psychologists have found that people feel closer to people who reveal personal information. ${ }^{17}$ A librarian could thus describe some of his or her own frustrations in using repositories as an effective way of establishing rapport with resistant users. The unexpected approach of bringing up the less desirable aspects of repositories-whether this refers to the technological steps that must be learned to submit one's work or the fact that depositing one's work in a repository is not a guarantee that it will be highly cited-can be disarming to the resistant user. This is particularly true of more resistant users who may have been expecting a strong hard-sell approach on the part of librarians. When suddenly faced with a more candid appeal the user may be thrown off balance psychologically, leaving him or her more vulnerable to information that is the opposite of what was anticipated and to possibly viewing that information in a more positive light.

If one way to disarm a user is to begin by discussing the negatives, a seemingly opposite approach that psychologists take is to reinforce the user's sense of self. Psychologists believe that one source of resistance stems from when a user's self-concept-which the user tries to protect from any source of undesired change-has been threatened in one way or another. A stable self-concept is necessary for the user to maintain a sense of order and predictability. Reinforcing the self-concept of the user should therefore make the user less likely to resist depositing work in a digital repository. Self-affirmed users are more open to information that challenges their beliefs and attitudes and are more open to suggestion. ${ }^{18}$

Thus before beginning a discussion of why users should deposit their research in repositories, it might help to first affirm the users' self-concept. This could be done, for example, by reminding them of how unbiased they are in their work or how important it is in their work to be open to new ideas and new approaches, or how successful they have been in their work as scholars. The affirmation should be subtle and not directly related to the repository situation, but it should remind them that they are openminded individuals who are not bound by tradition and that part of their success is attributable to their flexibility and adaptability. Once the users have been affirmed, librarians can then lead into a discussion of the importance of submitting scholarly research to repositories.

Self-generated affirmations may be even more effective. For example, another way to affirm the self would be to ask users to recall instances in which they successfully took a new approach or otherwise broke new ground or were innovative in some way. This could serve as a segue into a discussion of the repository as one more opportunity to be innovative. Once the self-concept has been boosted, the threatening quality of the message will be perceived as less disturbing and will be more likely to receive consideration.

A related strategy that psychologists employ to reduce resistance involves casting the user in the role of "expert." This is especially easy to do with scholars because they are experts in their fields. Casting the user in the role of expert can deactivate resistance by putting that person in the persuasive role, which creates a form of role reversal. ${ }^{19}$ Rather than the librarian being seen as the persuader, the scholar is placed in that role. By saying to the scholar, "You are the expert in the area of communicating your research to an audience, so you would know better why the digital repository is an alternative that deserves consideration once you understand how it works and how it may benefit you," you are empowering the user. Casting the user as an expert imparts a sense of control to the user. It helps to disable resistance by placing the user in a position of being predisposed to agree to the role he or she is being cast in, which also makes the user more prone to agree with the idea of using a digital repository.

\section{Priming and Imaging}

One important discovery that psychologists have made that has some bearing on user resistance is that even subtle manipulations can have a significant effect on one's judgments and actions. In an interesting experiment, psychologists told a group of students that they were to read an online newspaper, ostensibly to evaluate its design and assess how easy it was to read. Half of them read an editorial discussing a public opinion survey of youth 
consumer patterns that highlighted functional needs, and the other half read a similar editorial focusing on hedonistic needs. The students next viewed an ad for a new brand of shampoo that featured either a strong or a weak argument for the product. The results of the experiment indicated that students who read the functional editorial and were then subsequently exposed to the strong argument for the shampoo (a functional product) had a much more favorable impression of the brand than students who had received the mismatched prime. ${ }^{20}$

While it may seem that the editorial and the shampoo were unrelated, psychologists found that the subjects engaged in a process of elaborating the editorial, which then predisposed them to favor the shampoo. The presence of elaboration, which is a precursor to the development of attitudes, suggests that librarians could reduce users' resistance to digital repositories by first involving them in some form of priming activity immediately prior to any attempt to persuade them. For example, asking faculty to read a brief case study of a scholar who has benefited from involvement in open-access activity might serve as an effective prime. Another example might be to listen briefly to a speaker summarizing the individual, disciplinary, and societal benefits of sharing one's research with colleagues. Interventions like these should help mitigate any predisposition toward resistance on the part of users.

Imagining is a strategy related to priming that psychologists have found to be effective in reducing resistance. Taking their cue from insurance salesmen-who are trained to get clients to actively imagine what it would be like to lose their home or be in an accident-a group of psychologists conducted an experiment in which they divided a sample of homeowners who were considering the purchase of cable TV into two groups. One group was presented with the benefits of cable in a straightforward, informative way that described various features. The other group was asked to imagine themselves enjoying the benefits and all the possible channels and shows that they might experience and how entertaining it might be. The psychologists then administered a questionnaire. The results indicated that those participants who were asked to imagine the benefits of cable were much more likely to want cable TV and to subscribe to it than were those who were only given information about cable $\mathrm{TV}^{21}$ In other words, imagining resulted in more positive attitudes and beliefs.

This study suggests that librarians attempting to reduce resistance among users of digital repositories may need to do more than merely inform or describe to them the advantages of depositing their work. They may need to ask users to imagine in vivid detail what it would be like to receive periodic reports indicating that their work had been downloaded dozens or even hundreds of times. Librarians could ask them to imagine receiving e-mail or calls from colleagues indicating that they had accessed their work in the repository and were interested in learning more about it, or even possibly collaborating on research. Their imaginations could be further stimulated by asking them to think of what it would be like to have their work still actively preserved and available to their successors a century from now. Using the imagining strategy could potentially be significantly more effective in attenuating resistance than presenting arguments based on dry facts.

\section{Identification and liking}

Conscious processes like imagining are not the only psychological means of reducing the resistance of users to digital repositories. Unconscious processes can also be helpful. One example of such a process is what psychologists refer to as the "liking heuristic." This refers to the tendency of users to employ a rule-of-thumb method to decide whether to comply with requests from persons. This tendency results from users constantly being inundated with requests. Consequently, they need to simplify and streamline the decision-making process that they use to decide whether to cooperate with a request. The liking heuristic holds that users are more likely to help someone they might otherwise not help if they unconsciously identify with the person. At an unconscious level, the user may think that a person acts like them and dresses like them, and therefore the user identifies with that person and likes them enough to comply with their request.

In one experiment that psychologists conducted to see if people are more likely to comply with requests from people that they identify with, female undergraduates were informed that they would be participating in a study of first impressions. The subjects were instructed that they and a person in another room would each learn a little about one another without meeting each other. Each subject was then given a list of fifty adjectives and was asked to select the twenty that were most characteristic of themselves. The experimenter then told the participants that they would get to see each other's lists. The experimenter took the subject's list and then returned a short time later with what supposedly was the other participant's list, but was actually a list that the experimenter had filled out to indicate that either the subject had much in common with the other participant's personality (seventeen of twenty matches), some shared attributes (ten of twenty matches), or relatively few characteristics in common (three of twenty matches). The subject was then asked to examine the list and fill out a survey that probed their initial impressions of the other participant, including how much they liked them. At the end of the experiment, the two subjects were brought together and given credit for participating. The experimenter soon left the room and the confederate participant asked the other participant if she would read and critically evaluate an eight-page paper for an English class. The results of the experiment indicated that the more the participant thought she shared in 
common with the confederate, the more she liked her. The more she liked the confederate and experienced a perception of consensus, the more likely she was to comply with her request to critique the paper. ${ }^{22}$

Thus, when trying to overcome the resistance of users to depositing their work in a digital repository, it might make sense to consider who it is that is making the request. Universities sometimes host scholarly communication symposia that are not only aimed at getting faculty interested in open-access issues, but to urge them to submit their work to the institution's repositories. Frequently, speakers at these symposia consist of academic administrators, members of scholarly communication or open-access advocacy organizations, or individuals in the library field. The research conducted by psychologists, however, suggests that appeals to scholars and researchers would be more effective if they were made by other scholars and those who are actively engaged in research. Faculty are much more likely to identify with and cooperate with requests from their own tribe, as it were, and efforts need to be concentrated on getting faculty who are involved in and understand the value of repositories to articulate this to their colleagues. Researchers who can personally testify to the benefits of depositing their work are most likely to be effective at convincing other researchers of the value of doing likewise and will be more effective at reducing resistance. Librarians need to recognize who their potentially most effective spokespersons and advocates are, which the psychological research seems to suggest is faculty talking to other faculty.

\section{Perceived consensus and social modeling}

The processes of faculty identification with peers and perceived consensus mentioned above can be further enhanced by informing researchers that other scholars are submitting their work, rather than merely telling researchers why they should submit their work. Information about the practices of others may help change beliefs because of the need to identify with other in-group members. This is particularly true of faculty, who are prone to making continuous comparisons with their peers at other institutions and who are highly competitive by nature. Once they are informed of the career advantages of depositing their work (in terms of professional visibility, collaboration opportunities, etc.), and they are informed that other researchers have these advantages, this then becomes an impetus for them to submit their work to keep up with their peers and stay competitive. A perception of consensus is thus fostered-a feeling that if one's peers are already depositing their work, this is a practice that one can more easily agree to.

Psychologists have leveraged the power of identification by using social-norms research to inform people about the reality of what constitutes normative behavior as opposed to people's perceptions of it. For example, college students typically overestimate the amount of drinking that their peers engage in at parties. These inaccurate normative beliefs act as a negative influence, causing them to imbibe more because they believe that is what their peers are doing. By informing students that almost threequarters of their peers have less than three drinks at social gatherings, psychologists have had some success in reducing excessive drinking behavior by students. ${ }^{23}$

The power of normative messages is illustrated by a recent experiment conducted by a group of psychologists who created a series of five cards to encourage hotel guests to reuse their towels during their stay. The psychologists hypothesized that by appealing to social norms, they could increase compliance rates. To test their hypothesis, the researchers used a different conceptual appeal for each of the five cards. One card appealed to environmental concerns ("Help Save the Environment"), another to environmental cooperation ("Partner with Us to Save the Environment"), a third card appealed to the advantage to the hotel ("Help the Hotel Save Energy"), a fourth card targeted future generations ("Help Save Resources for Future Generations"), and a final card appealed to guests by making reference to a descriptive norm of the situation ("Join Your Fellow Citizens in Helping to Save the Environment"). The results of the study indicated that the card that mentioned the benefit to the hotel was least effective in getting guests to reuse their towels, and the card that was most effective was the one that mentioned that descriptive norm. ${ }^{24}$

This research suggests that if users who are resistant to submitting their work to digital repositories were informed that a larger percentage of their peers were depositing work than they realized, resistance may be reduced. This might prove to be particularly true if they learned that prominent or influential scholars were engaged in populating repositories with their work. This would create a social-norms effect that would help legitimize repositories to other faculty and help them to perceive the submission process as normal and desirable. The idea that accomplished researchers are submitting materials and reaping the benefits might prove very attractive to less experienced and less well-regarded faculty.

Psychologists have a considerable body of evidence in the area of social modeling that suggests that people will imitate the behavior of others in social situations because that behavior provides an implicit guideline of what to do in a similar situation. A related finding is that the more influential people are, the more likely it is for others to emulate their actions. This is even more probable for highstatus individuals who are skilled and attractive and who are capable of communicating what needs to be done to potential followers. ${ }^{25}$ Social modeling addresses both the cognitive dimension of how resistant users should behave and also the affective dimension by offering models that serve as a source of motivation to resistant users to change 
their behavior in the desired direction.

\section{Redefinition, consistency, and depersonalization}

Another strategy that psychologists use to reduce resistance among users is to change the definition of the situation. Resistant users see the process of submitting their research to the repository as an imposition at best. In their view, the last thing that they need is another obligation or responsibility to burden their already busy lives. Psychologists have learned that reframing a situation can reduce resistance by encouraging the user to look at the same phenomenon in a different way. In the current situation, resistant users should be informed that depositing their work in a digital repository is not a burden but a way to raise their professional profile as researchers, to expose their work to a wider audience, and to heighten their visibility among not only their peers but a much larger potential audience that would be able to encounter their work on the Web. Seen in this way, the additional work of submission is less of a distraction and more of a career investment.

Moreover, this approach leverages a related psychological concept that can be useful in helping to dissolve resistance. Psychologists understand that inconsistency has a negative effect on self-esteem, so persuading users to believe that submitting their work to a digital repository is consistent with their past behavior can be motivating. ${ }^{26}$ The point needs to be emphasized with researchers that the act of submitting their work to a digital repository is not something strange and radical, but is consistent with prior actions intended to publicize and promote their work. A digital repository can be seen as analogous to a preprint, book, journal, or other tangible and familiar vehicles that faculty have used countless times to send their work out into the world. While the medium might have changed, the intention and the goal are the same. Reframing the act of depositing as "old wine in new bottles" may help to undermine resistance.

In approaching highly resistant individuals, psychologists have discovered that it is essential to depersonalize any appeal to change their behavior. Instead of saying, "You should reduce your caloric intake," it is better to say, "It is important for people to reduce their caloric intake." This helps to deflect and reduce the directive, judgmental, and prescriptive quality of the request, thus making it less likely to provoke resistance. ${ }^{27}$ Suggestion can be much less threatening than prescription among users who may be suspicious and mistrusting. Reverting to a third-person level of appeal may allow the message to get through without it being immediately rejected by the user.

\section{Narrative, timing, and anticipation}

Psychologists recommend another strategy to help defuse highly resistant users that may be unwilling to submit their work to a repository. Rather than trying to prepare a strong argument based on reason and logic, psychologists believe that using a narrative approach may be more effective. This means conveying the facts about open access and digital repositories in the form of a story. Stories are less rhetorical and tend not to be viewed by listeners as attempts at persuasion. The intent of the communicator and the counterresistant message are not as overt, and the intent of the message might not be obvious until it has already had a chance to influence the listener. A well-crafted narrative may be able to get under the radar of the listener before the listener has a chance to react defensively and revert to a mode of resistance. In a narrative, beliefs are rarely stated overtly but are implied, and implied beliefs are more difficult to refute than overtly stated beliefs. Listening to a story and wondering how it will turn out tends to use up much of the cognitive attentional capacity that might otherwise be devoted to counterarguing, which is another reason why using a narrative approach may be particularly effective with users who are strongly resistant. The longer and more subtle nature of narratives may also make them less a target of resistance than more direct arguments. ${ }^{28}$

Using a narrative approach, the case for submitting work to a repository might be presented not as a collection of dry facts or statistics, but rather as a story. The protagonists are the researchers, and their struggle is to obtain recognition for their work and to advance scholarship by providing maximum access to the greatest audience of scholars and to obtain as much access as possible to the work of their peers so that they can build on it. The protagonists are thwarted in their attempts to achieve their ends by avaricious publishers who obtain the work of researchers for free and then sell it back to them in the form of journal and database subscriptions and books for exorbitant prices. These prices far exceed the rate of inflation or the budgets of universities to pay for them. The publishers engage in a series of mergers and acquisitions that swallow up small publishing firms and result in the scholarly publishing enterprise being controlled by a few giant firms that offer unreasonable terms to users and make unreasonable demands when negotiating with them. Presented in this dramatic way, the significance of scholar participation in digital repositories becomes magnified to an extent that it becomes more difficult to resist what may almost seem like an epic struggle between good and evil. And while this may be a greatly oversimplified example, it nonetheless provides a sense of the potential power of using a narrative approach as a technique to reduce resistance.

Introducing a time element into the attempt to persuade users to deposit their work in digital repositories can play an important role in reducing resistance. Given that faculty are highly competitive, introducing the idea not only that other faculty are submitting their work but that they are already benefiting as a result makes the 
proposition much more salient. It not only suggests that submitting work is a process that results in a desirable outcome, but that the earlier one's work is submitted, the more recognition will accrue and the more rapidly one's career will advance. ${ }^{29}$ Faculty may feel compelled to submit their work in an effort to remain competitive with their colleagues. One resource that may be particularly helpful for working with skeptical faculty who want substantiation about the effect of self-archiving on scholarly impact is a bibliography created by the Open Citation Project titled, "The Effect of Open Access and Downloads (Hits) on Citation Impact: A Bibliography of Studies." 30 It provides substantial documentation of the effect that open access has on scholarly visibility. An additional stimulus might be introduced in conjunction with the time element in the form of a download report. Showing faculty how downloads accumulate over time is analogous to arguments that investment counselors use showing how interest on investments accrues and compounds over time. This investment analogy creates a condition in which hesitating to submit their work results in faculty potentially losing recognition and compromising their career advancement.

An interesting related finding by psychologists suggests that an effective way to reduce user resistance is to have users think about the future consequences of complying or not complying. In particular, if users are asked to anticipate the amount of future regret they might experience for making a poor choice, this can significantly reduce the amount of resistance to complying with a request. Normally, users tend not to ruminate about the possibility of future disappointment in making a decision. If users are made to anticipate future regret, however, they will act in the present to try to minimize it. Studies conducted by psychologists show that when users are asked to anticipate the amount of future regret that they might experience for choosing to comply with a request and having it turn out adversely versus choosing to not comply and having it turn out adversely, they consistently indicate that they would feel more regret if they did not comply and experienced negative consequences as a result. ${ }^{31}$ In an effort to minimize this anticipated regret, they will then be more prone to comply.

Based on this research, one strategy to reduce user resistance to digital repositories would be to get users to think about the future, specifically about future regret resulting from not cooperating with the request to submit their work. If they feel that they might experience more regret in not cooperating than in cooperating, they might then be more inclined to cooperate. Getting users to think about the future could be done by asking users to imagine various scenarios involving the negative outcomes of not complying, such as lost opportunities for recognition, a lack of citation by peers, lost invitations to collaborate, an inability to migrate one's work to future technological platforms, and so on. This could be followed by a reminder to users that it is their choice-it is entirely up to them. This reminder that users have the freedom of choice may help to further counter any resistance generated as a result of instructions or inducements to anticipate regret. Indeed, psychologists have found that reinstating a choice that was previously threatened can result in greater compliance than if the threat had never been introduced. ${ }^{32}$

Offering users the freedom to choose between alternatives tends to make them more likely to comply. This is because having a choice enables users to both accept and resist the request rather than simply focus all their resistance on a single alternative. When presented with options, the user is able to satisfy the urge to resist by rejecting one option but is simultaneously motivated to accept another option; the user is aware that there are benefits to complying and wants to take advantage of them but also wants to save face and not give in. By being offered several alternatives that nonetheless all commit to a similar outcome, the user is able to resist and accept at the same time. ${ }^{33}$ For example, one alternative option to self-archiving might be to present the faculty member with the option of an authorpays publishing model. The choice of alternatives allows the faculty member to be selective and discerning so that a sense of satisfaction is derived from the ability to resist by rejecting one alternative. At the same time, the librarian is able to gain compliance because one of the other alternatives that commits the faculty member to depositing research is accepted.

\section{Options, comparisons, increments, and guarantees}

In addition to offering options, another way to erode user resistance to digital repositories is to use a comparative strategy. One technique is to first make a large request, such as "we would like you to submit all the articles that you have published in the last decade to the repository," and then follow this with a more modest request, such as "we would appreciate it if you would please deposit all the articles you have published in the last year." The original request becomes an "anchor" or point of reference in the mind of the user against which the subsequent request is then evaluated. Setting a high anchor lessens user resistance by changing the user's point of comparison of the second request from nothing (not depositing any work in the repository) to a higher value (submitting a decade of work). In this way, a high reference anchor is established for the second request, which makes it seem more reasonable in the newly created context of the higher value. ${ }^{34}$ The user is thus more likely to comply with the second request when it is framed in this way.

Using this comparative approach may also work because it creates a feeling of reciprocity in the user. When 
the requester scales down the request from the large one to a smaller one, it creates a sense of obligation on the part of the user to also make a concession by agreeing to the more modest request. The cultural expectation of reciprocity places the user in a situation in which they will comply with the lesser request to avoid feelings of guilt. ${ }^{35}$

For the most resistant users, breaking the request down into the smallest possible increment may prove helpful. By making the request seem more manageable, the user is encouraged to comply. Psychologists conducted an experiment to test whether minimizing a request would result in greater cooperation. They went door-to-door, soliciting contributions to the American Cancer Society, and received donations from 29 percent of households. They then made additional solicitations, this time asking, "Would you contribute? Even a penny will help!" Using this approach, donations increased to 50 percent. Even though the solicitors only asked for a penny, the amounts of the donations were equal to that of the original request. By asking for "even a penny," the solicitors made the request appear to be more modest and less of a target of resistance. ${ }^{36}$ Librarians might approach faculty by saying "if you could even submit one paper we would be grateful," with the idea that once faculty make an initial submission they will be more inclined to submit more papers in the future.

One final strategy that psychological research suggests may be effective in reducing resistance to digital repositories is to make sure that users understand that the decision to deposit their work is not irrevocable. With any new product, users have fears about what might happen if they try it and they are not satisfied with it. Not knowing the consequences of making a decision that they may later regret fuels reluctance to become involved with it. Faculty need to be reassured that they can opt out of participating at any time and that the repository sponsors will guarantee this. This guarantee needs to be repeated and emphasized as much as possible in the solicitation process so that faculty are frequently reminded that they are entering into a decision that they can reverse if they so decide. Having this reassurance should make researchers much less resistant to submitting their work, and the few faculty who may decide that they want to opt out are worth the reduction in resistance. ${ }^{37}$ The digital repository is a new phenomenon that faculty are unfamiliar with, and it is therefore important to create an atmosphere of trust. The guarantee will help win that trust.

\section{Conclusion}

The scholarly literature on digital repositories has given little attention to the psychology of resistance. Yet the ultimate success of digital repositories depends on overcoming the resistance of scholars and researchers to submit their work. Mandates rely on authority rather than persuasion to accomplish this and, as such, may represent a less-than-optimal solution to reducing user resistance. Mandates represent a failure to arrive at a meeting of the minds of advocates of open access, such as librarians, and the rest of the intellectual community.

Understanding the psychology of resistance is an important prerequisite to any effort to reduce it. Psychologists have assembled a significant body of research on resistance and how to address it. Some of the strategies that the research suggests may be effective, such as discussing resistance itself with users and talking about the negative effects of repositories, may seem counterintuitive and have probably not been widely used by librarians. Yet when other more conventional techniques have been tried with little or no success, it may make sense to experiment with some of these approaches. Particularly in the academy, where reason is supposed to prevail over authority, incorporating resistance psychology into a program aimed at soliciting faculty research seems an appropriate step before resorting to mandates.

Most strategies that librarians have used in trying to persuade faculty to submit their work have been conventional. They are primarily of a cognitive nature and are variations on informing and educating faculty about how repositories work and why they are important. Researchers have an important affective dimension that needs to be addressed by these appeals, and the psychological research on resistance suggests that a strictly rational approach may not be sufficient. By incorporating some of the seemingly paradoxical and counterintuitive techniques discussed earlier, librarians may be able to penetrate the resistance of researchers and reach them at a deeper, less rational level. Ideally, a mixture of rational and less-conventional approaches might be combined to maximize effectiveness. Such a program may not eliminate resistance but could go a long way toward reducing it. Future studies that test the effectiveness of such programs will hopefully be conducted to provide us with a better sense of how they work in real-world settings.

\section{References}

1. Charles W. Bailey Jr., "Institutional Repositories: DOA?," online posting, Digital Koans, Aug. 22, 2007, http://digital -scholarship.org/digitalkoans/2007/08/21/institutional -repositories-doa/ (accessed Apr. 21, 2010).

2. Dorothea Salo, "Yes, IRs Are Broken. Let's Talk About It," online posting, Caveat Lector, Sept. 5, 2007, http://cavlec. yarinareth.net/2007/09/05/yes-irs-are-broken-lets-talk-about -it/ (accessed Apr. 21, 2010).

3. EPrints Services, ROARMAP (Registry of Open Access Repository Material Archiving Policies) http://www.eprints .org/openaccess/policysignup/ (accessed July 28, 2009).

4. Richard K. Johnson, "Institutional Repositories: Partnering 
with Faculty to Enhance Scholarly Communication," D-Lib Magazine 8, no. 11 (2002), http://www.dlib.org/dlib/november02/ johnson/11johnson.html (accessed Apr. 2, 2008).

5. Bruce Heterick, "Faculty Attitudes Toward Electronic Resources," Educause Review 37, no. 4 (2002): 10-11.

6. Nancy Fried Foster and Susan Gibbons, "Understanding Faculty to Improve Content Recruitment for Institutional Repositories," D-Lib Magazine 11, no. 1 (2005), http:/ /www.dlib.org/ dlib/january05/foster/01foster.html (accessed July 29, 2009).

7. Suzanne Bell, Nancy Fried Foster, and Susan Gibbons, "Reference Librarians and the Success of Institutional Repositories," Reference Services Review 33, no. 3 (2005): 283-90.

8. Diane Harley et al., "The Influence of Academic Values on Scholarly Publication and Communication Practices," Center for Studies in Higher Education, Research \& Occasional Paper Series: CSHE.13.06, Sept. 1, 2006, http://repositories.cdlib.org/ cshe/CSHE-13-06/ (accessed Apr. 17, 2008).

9. Rea Devakos, "Towards User Responsive Institutional Repositories: A Case Study," Library High Tech 24, no. 2 (2006): 173-82.

10. Philip M. Davis and Matthew J. L. Connolly, “Institutional Repositories: Evaluating the Reasons for Non-Use of Cornell University's Installation of DSpace," D-Lib Magazine 13, no. 3/4 (2007), http:/ /www.dlib.org/dlib/march07/davis/03davis .html (accessed July 29, 2009).

11. Jihyun Kim, "Motivating and Impeding Factors Affecting Faculty Contribution to Institutional Repositories," Journal of Digital Information 8, no. 2 (2007), http://journals.tdl.org/jodi/ article/view/193/177 (accessed July 29, 2009).

12. Peter Suber, "Open Access Overview" online posting, Open Access News: News from the Open Access Environment, June 21, 2004, http:/ / www.earlham.edu/ peters/fos/overview .htm (accessed 29 July 2009).

13. See, for example, Jeffrey D. Ford and Laurie W. Ford, "Decoding Resistance to Change," Harvard Business Review 87, no. 4 (2009): 99-103.; John P. Kotter and Leonard A. Schlesinger, "Choosing Strategies for Change," Harvard Business Review 86, no. 7/8 (2008): 130-39; and Paul R. Lawrence, "How to Deal with Resistance to Change," Harvard Business Review 47, no. 1 (1969): 4-176.

14. Julia Zuwerink Jacks and Maureen E. O’Brien, "Decreasing Resistance by Affirming the Self," in Resistance and Persuasion, ed. Eric S. Knowles and Jay A. Linn (Mahwah, N.J.: Lawrence Erlbaum, 2004): 235-57.

15. Benjamin Margolis, "Notes on Narcissistic Resistance," Modern Psychoanalysis 9, no. 2 (1984): 149-56.

16. Ralph Grabhorn et al., "The Therapeutic Relationship as Reflected in Linguistic Interaction: Work on Resistance," Psychotherapy Research 15, no. 4 (2005): 470-82.

17. Arthur Aron et al., "The Experimental Generation of Interpersonal Closeness: A Procedure and Some Preliminary Findings," Personality E Social Psychology Bulletin 23, no. 4 (1997): 363-77.

18. Geoffrey L. Cohen, Joshua Aronson, and Claude M. Steele, "When Beliefs Yield to Evidence: Reducing Biased Evaluation by Affirming the Self," Personality \& Social Psychology Bulletin 26, no. 9 (2000): 1151-64.

19. Anthony R. Pratkanis, "Altercasting as an Influence Tactic," in Attitudes, Behavior and Social Context: The Role of Norms and Group Membership, ed. Deborah J. Terry and Michael A.Hogg (Mahwah, N.J.: Lawrence Erlbaum, 2000): 201-26.
20. Curtis P. Haugtvedt et al., "Consumer Psychology and Attitude Change," in Knowles and Linn, Resistance and Persuasion, 283-96.

21. Larry W. Gregory, Robert B. Cialdini, and Kathleen M. Carpenter, "Self-Relevant Scenarios as Mediators of Likelihood Estimates and Compliance: Does Imagining Make It So?" Journal of Personality \& Social Psychology 43, no. 1 (1982): 89-99.

22. Jerry M. Burger, "Fleeting Attraction and Compliance with Requests," in The Science of Social Influence: Advances and Future Progress, ed. Anthony R. Pratkanis (New York: Psychology Pr., 2007): 155-66.

23. John D. Clapp and Anita Lyn McDonald, "The Relationship of Perceptions of Alcohol Promotion and Peer Drinking Norms to Alcohol Problems Reported by College Students," Journal of College Student Development 41, no. 1 (2000): 19-26.

24. Noah J. Goldstein and Robert B. Cialdini, "Using Social Norms as a Lever of Social Influence," in The Science of Social Influence: Advances and Future Progress, ed. Anthony R. Pratkanis (New York: Psychology Pr., 2007): 167-90.

25. Dale H. Schunk, "Social-Self Interaction and Achievement Behavior," Educational Psychologist 34, no. 4 (1999): 219-27.

26. Rosanna E. Guadagno et al., "When Saying Yes Leads to Saying No: Preference for Consistency and the Reverse Foot-inthe-Door Effect," Personality \& Social Psychology Bulletin 27, no. 7 (2001): 859-67.

27. Mary Jiang Bresnahan et al., "Personal and Cultural Differences in Responding to Criticism in Three Countries," Asian Journal of Social Psychology 5, no. 2 (2002): 93-105.

28. Melanie C. Green and Timothy C. Brock, "In the Mind's Eye: Transportation-Imagery Model of Narrative Persuasion," in Narrative Impact: Social and Cultural Foundations, ed. Melanie C. Green, Jeffrey J. Strange, and Timothy C. Brock (Mahwah, N.J.: Lawrence Erlbaum, 2004): 315-41.

29. Oswald Huber, "Time Pressure in Risky Decision Making: Effect on Risk Defusing," Psychology Science 49, no. 4 (2007): 415-26.

30. The Open Citation Project, "The Effect of Open Access and Downloads ('Hits') on Citation Impact: A Bibliography of Studies," July 17, 2009, http://opcit.eprints.org/oacitation -biblio.html (accessed July 29, 2009).

31. Matthew T. Crawford et al., "Reactance, Compliance, and Anticipated Regret," Journal of Experimental Social Psychology 38, no. 1 (2002): 56-63.

32. Nicolas Gueguen and Alexandre Pascual, "Evocation of Freedom and Compliance: The 'But You Are Free of . . .' Technique," Current Research in Social Psychology 5, no. 18 (2000): 264-70.

33. James P. Dillard, "The Current Status of Research on Sequential Request Compliance Techniques," Personality \& Social Psychology Bulletin 17, no. 3 (1991): 283-88.

34. Thomas Mussweiler, "The Malleability of Anchoring Effects," Experimental Psychology 49, no. 1 (2002): 67-72.

35. Robert B. Cialdini and Noah J. Goldstein, "Social Influence: Compliance and Conformity," Annual Review of Psychology 55 (2004): 591-21.

36. James M. Wyant and Stephen L. Smith, “Getting More by Asking for Less: The Effects of Request Size on Donations of Charity," Journal of Applied Social Psychology 17, no. 4 (1987): 392-400.

37. Lydia J. Price, "The Joint Effects of Brands and Warranties in Signaling New Product Quality," Journal of Economic Psychology 23, no. 2 (2002): 165-90. 